\title{
Soil aggregate stability and carbon fractions in soils containing organic matter additions in intensive greenhouse vegetable fields
}

\author{
chao fei ${ }^{1}$, Xiaodong Ding ${ }^{1}$, Shirong $Z_{\text {hang }}{ }^{1}$, junliang li $^{1}$, and bin liang ${ }^{1}$ \\ ${ }^{1}$ Qingdao Agricultural University
}

June 9, 2020

\begin{abstract}
Soil degradation in intensive greenhouse vegetable fields is a major agricultural concern since these soils are widely used for food production. Organic materials play essential roles in soil aggregate stability and carbon sequestration. We conducted a 5 -year fertilization study in intensively farmed greenhouse vegetable fields to examine the effects of added organic matter on soil aggregate stability, organic carbon fractions and their interrelationships. Four experimental treatments were included: 1) mineral fertilizer only (CK); 2) mineral fertilizer combined with chicken manure (CM); 3) rice husks (RH); and 4) chicken manure plus rice husks $(\mathrm{MH})$. These organic materials applications significantly improved the proportion of $>0.25$ mm aggregates while decreasing the ratio of soil $<0.25 \mathrm{~mm}$ aggregates. The mean weight diameters of water-stable soil aggregates was increased with organic fertilizer addition and were ranked RH [?] $\mathrm{MH}>\mathrm{CM}>\mathrm{CK}$. The organic materials applications treatments had a greater soil organic matter, humic acid and humus than the CK. RH addition significantly increased the proportion of $>2$ mm aggregates, possibly due to higher humus and polysaccharide carbon content. CM application increased soil Fe-ox content due to soil acidification and increased aliphatic carbon content that in turn increased the proportion of 1-2 mm aggregates. The study indicated a possible advantage for chicken manure and rice husk incorporation for the generation and persistence of stable soil aggregates.
\end{abstract}

\section{Introduction}

Greenhouses are widely used to maintain controlled environments for optimal vegetable production and to maximize profits (Pratiwi et al., 2016). However, the high rates of successive planting and removal of crop residues deplete soil organic carbon and lead to soil degradation (Zhao et al., 2019). In addition, elevated greenhouse temperatures, extensive use of chemical fertilizers and high irrigation frequencies have negative impacts on soil aggregation and aggregate stability in greenhouse vegetable production systems (Wang et al., 2016). Consequently, soil degradation has become a core problem that affects the sustainable and green development of greenhouse vegetable cultivation (Pratiwi et al., 2016).

Organic materials in soils are key components necessary for improving crop production and soil aggregate stability (Mamedov et al., 2014; Zhao et al., 2018). Results of similar field trial showed that long-term organic materials application promoted the formation of soil macro aggregates $(>0.25 \mathrm{~mm})$ and increased aggregate stability (Zhao et al., 2018). Organic materials also generally increase soil organic matter (SOM) content, which are an essential binding agent for aggregates (Zhao et al., 2017). In particular, macro-aggregates are formed from the combination of micro-aggregates $(0.05-0.25 \mathrm{~mm})$ and SOM. Stable macroaggregates are found to be richer in young and decomposable SOM than microaggregates (Janik et al., 2007). Aggregates stability is affected by both SOM content as well as composition (Lehmann et al., 2001). For example, soil humic substances (HM) are the primary binding agents for micro-aggregates (Six et al. 2000). In contrast, polysaccharides are the organic cementing substances and have only transient binding effects on macro-aggregates formation (Klotzbücher et al., 2013; Sarker et al., 2018). 
Multivalent metals also play profoundly important roles in the stability and size distribution of soil aggregates (Wang et al., 2016). Polycrystalline and amorphous iron is more effective than free iron in stabilizing soil aggregates (Klotzbücher et al., 2013; Wen et al., 2019; Guo et al., 2020). Exchangeable $\mathrm{Ca}^{2+}$ can also improve soil structure through bridging with clay minerals and SOM (Zhu et al., 2016). In general, formation of soil aggregates involves absorption of organic matter into clay and multivalent metal cations serve as bridges for SOM participation in the formation and stability of soil aggregates (Wang et al., 2015).

The effects and mechanisms of fertilization on stability and size distribution of soil aggregates have been well documented although these studies have primarily focused on the open field crop planting system (Wang et al., 2016; Zhao et al., 2017). Less is known about the responses of stability and size distribution of soil aggregates to the long-term application of organic materials in greenhouse vegetable cultivation soil. In particular, different types of organic materials possess variable carbon (C) content and composition and these differentially affect stabilities and turnover rates of aggregates (Mamedov et al., 2014; Sarker et al., 2018). The objectives of the present study were (i) to evaluate the effects of application of organic material on soil stable aggregates and organic carbon fractions (ii) to identify the associated mechanisms of organic material addition on soil aggregate formation in greenhouse vegetable soils and (iii) to provide suggestions for developing optimal organic material management strategies in sustainable greenhouse vegetable production.

\section{Materials and Methods}

\subsection{Study site and experimental design}

Field experiments were conducted in Shouguang city, Shandong province (36 $\left.55^{\prime} \mathrm{N}, 118 \mathrm{deg} 45^{\prime} \mathrm{E}\right)$. The soil was classified as molic gleysol based on the FAO-UNESCO World Soil Map. The basic chemical properties of the soil $(0-30 \mathrm{~cm})$ were as follows: $\mathrm{pH} 7.35$ (1:5, soil/water), SOM $14.9 \mathrm{~g} \mathrm{~kg}^{-1}$, available N (AN) $148.9 \mathrm{mg}$ $\mathrm{kg}^{-1}$, available P (AP) $117 \mathrm{mg} \mathrm{kg}^{-1}$ and available $\mathrm{K}(\mathrm{AK}) 223 \mathrm{mg} \mathrm{kg}$.

Field experiments started in 2015. Tomatoes were the sole crop and were planted in the autumn-winter season (August-January) and in the winter-spring season (February to June) each year, respectively. The experiments contained 4 treatment groups: (1) CK, no organic fertilization, (2) CM, 30 t chicken manure ha per season, (3) RH, $30 \mathrm{t}$ rice husk per season, (4) MH, $10 \mathrm{t}$ air-dried chicken manure and $20 \mathrm{t}$ rice husk per season. Each treatment adopted a randomized blocked-plot design containing 3 replicates. The total area of each replicate plot was $41.0 \mathrm{~m}^{2}$.

The organic nutrients used in these experiments was commercial chicken manure containing $257.2 \mathrm{~g} \mathrm{C} \mathrm{kg}^{-1}$, $16.3 \mathrm{mg} \mathrm{N} \mathrm{kg}-1,19.4 \mathrm{mg} \mathrm{P} \mathrm{kg}^{-1}$ and $8.4 \mathrm{mg} \mathrm{K} \mathrm{kg}^{-1}$. The $\mathrm{C}, \mathrm{N}, \mathrm{P}$ and $\mathrm{K}$ contents in the rice husks were $507.5 \mathrm{~g} \mathrm{C} \mathrm{kg}^{-1}, 4.6,1.4$ and $7.9 \mathrm{mg} \mathrm{kg}^{-1}$, respectively (Table S1). In addition, all plots received the same chemical fertilized. $363 \mathrm{~kg} \mathrm{ha}^{-1} \mathrm{~N}, 296 \mathrm{~kg} \mathrm{ha}^{-1} \mathrm{P}_{2} \mathrm{O}_{5}$ and $523 \mathrm{~kg} \mathrm{ha}^{-1} \mathrm{~K}_{2} \mathrm{O}$ that were incorporated into the soils. Organic materials and $1000 \mathrm{~kg} \mathrm{ha}^{-1}$ compound fertilizer ( $20 \%, \mathrm{P}_{2} \mathrm{O}_{5} 20 \%, \mathrm{~K}_{2} \mathrm{O} 20 \%$ ) were applied with soil ploughing before planting for each season. During the tomato growth stage, the remaining chemical fertilizer (water-soluble compound fertilizer, $\mathrm{N} 20 \%, \mathrm{P}_{2} \mathrm{O}_{5} 20 \%, \mathrm{~K}_{2} \mathrm{O} 20 \%$ and $\mathrm{N} 16 \%, \mathrm{P}_{2} \mathrm{O}_{5} 6 \%, \mathrm{~K}_{2} \mathrm{O} 40 \%$ ) was applied with furrow irrigation at 9 times over each season at 75-100 $\mathrm{mm}$ each time.

\subsection{Soil sampling and analyses}

Five soil columns with $10 \mathrm{~cm}$ diameter in 0-30 cm were randomly taken from each treatment plot in April 2019. Each sample was mixed thoroughly and passed through an 8-mm sieve by gently breaking the soil clods and avoiding soil deformation from mechanical compression. Pebbles, plant residue and creatures were removed and the soil was air-dried at room temperature. A portion of the subsample was passed through a 2-mm sieve to investigate the soil organic matter, and the remaining soil was used to determine the aggregate size distribution.

The soil $\mathrm{pH}$ was measured with a soil/distilled water ratio of 1:2.5. Exchangeable $\mathrm{Na}, \mathrm{Ca}$ and $\mathrm{Mg}$ were extracted in $5 \mathrm{mM}$ EDTA-NaAOc (soil: solution ratio of 5:1). Elemental analyses was performed using atomic emission spectroscopy with an Optima 8000 ICP-OES instrument (PerkinElmer, Waltham, MA, USA). Amorphous $\mathrm{Fe}$ and $\mathrm{Al}$ oxides (Fe-ox and $\mathrm{AL}-\mathrm{ox}$ ) were extracted using the ammonium oxalate method 
(Li, 1997). For each sample, $0.5 \mathrm{~g}$ air-dried soil was placed into a $50 \mathrm{~mL}$ centrifuge tube and $25 \mathrm{~mL} 200 \mathrm{M}$ ammonium oxalate was added (soil: solution $=1: 50$ ). The mixture was shaken for $2 \mathrm{~h}$ in the dark and then centrifuged immediately at $4000 \mathrm{rpm}$. The supernatant was diluted 5 times and the $\mathrm{Fe}$ and $\mathrm{Al}$ content in the solution were determined using ICP.

\subsection{Soil aggregate stability}

To obtain different size fractions of water-stable aggregates, $50 \mathrm{~g}$ of soil samples were placed on the top of a sieve series with mesh sizes of $2,1,0.5$ and $0.25 \mathrm{~mm}$ from top to bottom. The sieve set was placed on the shock rack of a aggregate analyzer, submerged in water, and shaken with amplitude of $3 \mathrm{~cm}$ at 30 oscillations per minute for $30 \mathrm{~min}$. The obtained size fractions at each sieve were washed into a beaker and then dried at $60 \mathrm{deg} \mathrm{C}$ for $24 \mathrm{~h}$ and weighed. Each fraction was weighed to calculate the dry aggregate stability expressed by mean weight diameter (MWD). Mean weight diameter (MWD) was calculated as:

$$
\mathrm{MWD}=\sum_{i=1}^{n} X_{i} W_{i}
$$

The percentage of water-stable aggregate (WSA) was calculated as:

$$
\mathrm{WSA}=100 \times \frac{\sum_{i=1}^{4} W_{i}}{w}
$$

where $i$ is the average diameter of $i^{\mathrm{th}}$ size fraction of the aggregate, wi is the mass of $i^{\mathrm{th}}$ size fraction of the aggregate, and $w$ is the total mass of all size fractions of the aggregate. $\mathrm{i}=1,2, \ldots, 5$ represent the aggregate size $>2.0 \mathrm{~mm}, 2.0-1.0 \mathrm{~mm}, 1.0-0.5 \mathrm{~mm}, 0.5-0.25 \mathrm{~mm}$ and $<0.25 \mathrm{~mm}$, respectively.

\subsection{Carbon content of different soil organic matter}

The SOM of soil samples were determined using the dichromate oxidation method (Kuwatsuka et al., 1992) and humus composition was analyzed as previously described (Dou 2010). Briefly, soil was extracted in a mixed alkali solution $\left(\mathrm{NaOH}+\mathrm{Na}_{4} \mathrm{P}_{2} \mathrm{O}_{7}\right)$ and then centrifuged. The supernatant represented humic extractable substance (HM) and $30 \mathrm{~mL}$ was acidified to $\mathrm{pH} 1$ to separate humic acid (HA) from fulvic acid (FA). The precipitate was composed of HA while FA remained in solution. HA was re-dissolved with 0.05 $\mathrm{M} \mathrm{NaOH}$. All solutions were used for measurements. HA isolation and purification followed the procedure described by the International Humic Substances Society (Kuwatsuka et al., 1992). Briefly, soil was decalcified with $\mathrm{HCl}$ and extracted with $\mathrm{NaOH}$ for $24 \mathrm{~h}$ and then centrifuged. The supernatant contained the humic extractable substance fraction and was acidified to $\mathrm{pH}$ 1.0. The precipitate contained HA and was dialyzed against filter membrane to eliminate excess salts and then freeze-dried.

\subsection{Analysis of soil surface functional groups}

Soil surface functional groups were investigated using Fourier transform mid-infrared photoacoustic spectroscopy (FTIR-PAS, Peltre et al., 2014) using a Nicolet 6700 FTIR spectrometer (Thermo Scientific, Pittsburg, PA, USA) equipped with a PA301 photoacoustic (PAS) detector with a cantilever microphone (Gasera, Tur$\mathrm{ku}$, Finland). Samples of soils and fractions for mean diffuse reflectance FTIR (DRIFTS) analyses were ball milled and dried overnight at $32^{\circ} \mathrm{C}$ and packed in $10 \mathrm{~mm}$ ring cups and inserted into the PAS detector using $\mathrm{He}$ as purge gas. Spectra were recorded from an average of 32 scans at a resolution of $4 \mathrm{~cm}^{-1}$ (i.e. with 2 $\mathrm{cm}^{-1}$ data-point intervals) in the range $4000-500 \mathrm{~cm}^{-1}$.

The peak at $1160 \mathrm{~cm}^{-1}$ was assigned to stretching $\mathrm{C}-\mathrm{O}$ in carbohydrates, nucleic acids and proteins (Janik et al., 2007). The peak at $1390 \mathrm{~cm}^{-1}$ was aliphatic $\mathrm{C}-\mathrm{H}$, with potential contributions from carboxylates (C-O) (Parikh et al., 2014). The peak at $1620 \mathrm{~cm}^{-1}$ was assigned to predominately aromatic $\mathrm{C}=\mathrm{C}$ stretching and asymmetric -COO- stretching (Baes \& Bloom, 1989) but possibly also $\mathrm{C}=\mathrm{O}$ vibrations (Stevenson, 1994). The double peak centered at $2930 \mathrm{~cm}^{-1}$ of the aliphatic $\mathrm{C}-\mathrm{H}$ stretching (Baes \& Bloom, 1989) was 
superimposed on the broad O-H peak centered at $3400 \mathrm{~cm}^{-1}$ (Movasaghi et al., 2008). For peak area investigations, wave-numbers of functional groups associated with non-organic compounds such as silicates and alumino-iron oxides were avoided. The four peaks (1160, 1390, 1620 and $\left.3400 \mathrm{~cm}^{-1}\right)$ were used for further treatments and were assigned to different organic functional groups and their potential stabilities were based on current literature (Table 1).

Some organic materials and soil chemical properties are listed in the supporting information to assist in data interpretation of the present study, including exchangeable C, N, P, K and other element concentrations, functional groups in chicken manure and rice husks and soil microbial biomass carbon (MBC).

\subsection{Statistical analysis}

Significant differences of the soil properties among treatments were tested with one-way ANOVA followed by the least significant difference $(L S D)$ at $p<0.05$. Principal component analysis (PCA) and redundancy analysis (RDA) were implemented using CANOCO software (Version 4.5, Microcomputer Power, Ithaca, NY, USA) and were applied to visualize the stability and size distribution of soil aggregates using types of organic material application as the constraining variable and the relationships between related soil properties and aggregate size distributions. Monte Carlo tests were used to determine the main effectors of mean weight diameter and aggregate size. All statistical analyses were carried out using SPSS 20.0 (IBM, Chicago, IL, USA).

\section{Results}

\subsection{Stability and size distribution of soil aggregates}

The amount of large macro-aggregates $(>2.0 \mathrm{~mm})$ in the rice husk $(\mathrm{RH})(8.5 \%)$ and manure-rice husk $(\mathrm{MH})$ $(8.7 \%)$ treatments were higher than that for the control (CK) treatment $(6.7 \%)$. We found no significant differences in the amount of large macro-aggregates between the chicken manure $(\mathrm{CM})$ and CK treatments. The amount of aggregates in the $2.0-1.0 \mathrm{~mm}$ and $1.0-0.5 \mathrm{~mm}$ groups were greater for all 3 organic fertilization treatments. Moreover, the amount of $2.0-1.0 \mathrm{~mm}$ aggregates in the $\mathrm{CM}$ and $\mathrm{MH}$ were greater than in $\mathrm{RH}$. Compared with $\mathrm{CK}$ treatment, $\mathrm{CM}, \mathrm{RH}$ and $\mathrm{MH}$ treatments exhibited significant decrease at the distribution of aggregates within the $<0.25 \mathrm{~mm}$ particle sizes (Fig. 1a).

The mean weight diameter (MWD) and water stable (WSA) soil aggregates strongly reflect total aggregate distribution and stability. The MWD was significantly increased in $\mathrm{RH}$ and $\mathrm{MH}$ treatments and indicated that long-term application of rice hulls enhanced aggregate stability (Fig. 1b). The WSA values also increased with organic fertilizer addition compared with control and $\mathrm{RH}$ and $\mathrm{MH}$ values exceeded those of the $\mathrm{CM}$ treatment (Fig. 1c).

\subsection{Soil carbon content and composition}

Over the 5 years of this study, SOM levels were significantly increased with the organic fertilizer applications as expected $(p<0.05)$. The SOM accumulation in the RH treatments was $20.3 \mathrm{~g} \mathrm{~kg}^{-1}$ and was significantly higher than that for the CM treatment $\left(16.8 \mathrm{~g} \mathrm{~kg}^{-1}\right)$. The amount of organic carbon was greatest in the HM fraction followed by HA and FA for all treatments (Fig. 2). The organic carbon in the HM fraction was significantly greater with the application of organic material, and both rice husk (RH and $\mathrm{MH}$ ) treatments were significantly higher than for the CM soil. The amounts of organic carbon in the HA fraction were increased with organic material addition in which the maximal $4.4 \mathrm{~g} \mathrm{~kg}^{-1}$ was found for RH treatment. The $\mathrm{SOC}$ in the FA fraction were ranked in the order $\mathrm{CM}>\mathrm{MH}>\mathrm{RH}[?] \mathrm{CK}$.

\subsection{DRIFTS analysis}

We examined the surface properties of our experimental soils using DRIFTS analysis. The spectra of the 4 soils generally featured common peaks with different intensities. For example, the $1160 \mathrm{~cm}^{-1}$ peak was the primary contributor to the total relative area in the soil spectra followed by peaks at 3400, 1620 and 1390 $\mathrm{cm}^{-1}$ (Fig. 3). The DRIFTS peaks of the four investigated bands were affected significantly by fertilizer treatment $(p<0.05)$ (Table 2). The average relative area of the $1390 \mathrm{~cm}^{-1}$ peak was $8.00 \%$ in CK treatment 
that was increased by 22.0, 17.6 and $13.4 \%$ in $\mathrm{MH}$, CM and $\mathrm{RH}$ treatments, respectively. The relative peak areas at $1620 \mathrm{~cm}^{-1}$ also varied significantly across all the four treatments; the smallest peak area was found for $\mathrm{MH}$ and the largest for CK $(p<0.05)$. The relative $1160 \mathrm{~cm}^{-1}$ peak areas were increased slightly with organic material addition and RH was the largest. Similarly, the $3400 \mathrm{~cm}^{-1}$ relative peak area was increased in $\mathrm{CM}$ and $\mathrm{MH}$ treatments, but was decreased in $\mathrm{RH}$ treatment (Table 2).

\subsection{Soil properties associated with aggregate formation}

The soil $\mathrm{pH}$ values were decreased in the $\mathrm{CM}$ treatment compared with other three treatments. In addition, the Fe-ox content was significantly increased with organic material application compared with CK, especially for $\mathrm{CM}$ and $\mathrm{MH}$. The soil Al-ox content for CM treatments was increased above $\mathrm{CK}$ (Table 3). The soil $\mathrm{Na}^{+}$ content in the $\mathrm{CM}$ treatment was significantly higher than the other three treatments $(\mathrm{CM}>\mathrm{MH}>\mathrm{RH}>\mathrm{CK})$. The soil $\mathrm{Ca}^{2+}$ level in soil was decreased by 29.2 and $21.0 \%$ for $\mathrm{CM}$ and $\mathrm{MH}$ respectively. However, no significant differences were found for soil $\mathrm{Mg}^{2+}$ levels among the four treatments (Table 3 ).

\subsection{Correlation analyses between soil properties and soil aggregate}

Principal component analysis (PCA) was used to explore the effects of organic material input on the soil aggregate stability and size distribution. The first principal coordination axis (accounting for $63.3 \%$ of the variation) was significantly different between CK and the other three treatments. CK and CM were located on the positive side of the $\mathrm{x}$-axis while $\mathrm{RH}$ and $\mathrm{MH}$ were on the negative side suggesting a significant impact of $\mathrm{RH}$ and $\mathrm{MH}$ on the soil aggregate stability and size distribution. The second principal coordination axis accounted for $28.9 \%$ of the variation among the samples and clearly separated CK and CM (Fig. 4).

Redundancy analysis (RDA) indicated that the contribution of the tested soil parameters to the soil aggregate stability and size distribution were explained by the different soil humus, carbon functional groups and mineral ions. The RDA (a) illustrated that soil aggregate stability and size distribution were significantly affected by HM-C $(\mathrm{F}=22.2, p=0.002)$, SOM $(\mathrm{F}=18.9, p=0.002)$ and HA-C $(\mathrm{F}=13.3, p=0.002)$. MWD, WAS and the proportion of $>0.25 \mathrm{~mm}$ aggregates were positively correlated with SOM, HM and HA while the proportion of $<0.25 \mathrm{~mm}$ aggregates was negatively correlated with these. The proportion of $2-1 \mathrm{~mm}$ aggregates had significant positive correlations with HA (Fig. 5a).

The RDA (b) showed that polysaccharide-C, aliphatic-C and carboxyl or amidogen - C were significantly correlated with the soil aggregate stability and size distribution $(p<0.05)$. All carbon functional groups in the RDA model had positive correlations with MWD, WSA and the proportion of $>0.25 \mathrm{~mm}$ aggregates, but were negative with the proportion of $<0.25 \mathrm{~mm}$ aggregates (Fig. 5b).

The RDA(c) showed that Fe-ox and $\mathrm{Ca}^{2+}$ had significant positive effects on the MWD, WSA and the proportion of $>0.25 \mathrm{~mm}$ aggregates while the proportion of $>0.25 \mathrm{~mm}$ aggregates was negatively correlated with the Fe-ox and $\mathrm{Ca}^{2+}$ (Fig. 5c).

\section{Discussion}

\subsection{Effects of organic material application on soil aggregate}

The effects of organic material application on our experimental soil aggregates were profound. These organic materials applications significantly improved the proportion of $>0.25 \mathrm{~mm}$ aggregates while decreasing the ratio of soil $<0.25 \mathrm{~mm}$ aggregates (Fig. 1). These data agree with the results of previous studies using straw returned to the fields post-harvest and manure addition that promoted the formation of the large and small macro-aggregates and decreased the silt plus clay fraction (Zhao et al., 2018; Wang et al., 2015; Mamedov et al., 2014). We also found that organic material applications induced an obviously increase of WSA, especially RH and MH treatments. Meanwhile, the increase of MWD was only observed in RH and $\mathrm{MH}$ treatments (Fig, 1c). These results confirm the effectiveness of rice husks amendments to increase soil aggregate stability in the intensively managed greenhouse soils. Rice husks have been shown to improve soil physical properties (Chien et al., 2011; Anikwe 2000). This may be the result of the large specific surface 
area that can alter the total number of pores per volume and increase the bulk density (Pratiwi et al., 2016). This pore size distribution can directly affect soil structure development (Chien et al., 2011).

\subsection{Effects of organic material application on soil carbon fractions}

Total SOM levels were significantly increased by continuous organic material application in the intensively managed greenhouse soils and RH levels were greater that MH and CM (Fig. 2a). This is most likely related to a greater total carbon input for RH resulting in greater SOM accumulation (Fig. S1). Moreover, the degradation of rice husk releases lipids and waxes that can form a hydrophobic coating around the SOM and act as a protective barrier against microbial decomposition (Pratiwi et al., 2016).

Soil humic fractions play a central role in stabilizing soil organic carbon pool (Fig 2,Xu et al., 2018). After five years of different organic amendments, soil HM levels had increased compared with CK (Fig. 2b). Humus$\mathrm{C}$ could be tightly bound to mineral surfaces to form metal-organic-mineral coatings through adsorption by ligand exchange with protonated surface hydroxyls (Tadashi and Randy, 2016). This acted to prevent microbial decomposition and mineralization (Zhao et al., 2019). Among the three organic amendments, $\mathrm{RH}$ resulted in the highest concentrations of HA while no differences were found between $\mathrm{CM}$ and $\mathrm{MH}$. This result is consistent with a previous study that found application of mineral fertilizer plus maize straw or maize straw-derived biochar increased HA concentrations (Zhang et al., 2019). Alterations in soil HA were primarily due to the entry of HA extracted from straw into the soil (Zhang et al., 2011). In addition, Kuzyakov (2010) indicated that priming effects on SOM mineralization increased linearly with C input at low input rates. Moreover, addition of manure alone or accompanied with rice husks increased microbial biomass as evidenced by the increase of MBC content and promoted HA decomposition (Fig. S3).

Generally speaking, FA can provide agreater amount of bioavailable carbon as an electron donor for microbial respiration than HA and HM (Qiao et al., 2019). However, FA are a mixture of complex organic compounds and the majority are insoluble in water at neutral $\mathrm{pH}$. This leads to low bioavailability of FA for microbes (Stevenson 1994). This might partly explain why the CM soils had higher FA levels than the other treatments (Fig. 2).

We also found a lower proportion of aromatic groups together with a higher proportion of aliphatic, polysaccharide and carboxyl or amidogen groups in the soils that contained added organic material (Table 2). This supports the theory of a rapid, microbial-induced improvement in activated soil carbon functional groups after the addition of fresh organic residues that were rich in labile polysaccharides (Sarker et al., 2018). Compared with chicken manure, rice husks contained a larger proportion of polysaccharides and smaller proportions of aromatics (Fig. S2 and Table S2). In agreement with this we found that the carbon functional groups in CM soils were richer in aromatics while the rice husk soils contained higher percentages of polysaccharides (Fig. 3 and Table 2).

Organic material application also can affect the soil ion content either directly by adding ions or indirectly by altering other soil properties such as $\mathrm{pH}$ or SOM (Adhikari and Yang, 2015). The pH of our CM soils was less than for the other treatments (Table 3). Decreased soil pH can mobilize exchangeable $\mathrm{Fe}$ and $\mathrm{Al}$ while decreasing exchangeable $\mathrm{Ca}$ and $\mathrm{Mg}$ in calcareous soils (Table 3) (Klotzbucher et al., 2013; Wen et al., 2019). In particular, our CM soils contained greater amounts of organic structures recalcitrant to biodegradation (aliphatic and aromatic fractions). These compounds would then be preferentially sorbed onto reactive poorly crystalline Fe oxides (Adhikari and Yang, 2015; Wen et al., 2019; Guo et al., 2020). We found a significant positive correlation $(p<0.05)$ between aliphatic and aromatic fractions and Fe-ox fractions (Table S4).

\subsection{The linkage between soil aggregate and soil chemical properties}

Our RDA revealed that SOM and humus composition except for FA-C were significant predictors of soil aggregate stability and size distribution $(p<0.05)$. This is consistent with the theory that SOM is a key stabilizing agent for aggregates, especially for soils dominated 2:1 by clay minerals (Mamedov et al., 2014). HA can form a bridge between soil clay platelets (Sander et al., 2004) and increase aggregate resistance 
to slaking by inducing hydrophobic conditions (Song et al., 2018). The higher concentrations of HM in the $\mathrm{RH}$ and $\mathrm{MH}$ soils of the present study may have matched the higher MWD and WSA, so that rice husk addition had observable effects on soil aggregate stability (Anikwe, 2000). The amount of humic-like substances synthesized from plant residues remaining in soil determines soil aggregate stability (Parwada and Van, 2019). These results confirm the observations of other researchers that HM substances are usually considered as the major binding agents of macro-aggregates (Six et al., 2000).

At the molecular level, our study revealed that polysaccharide - $\mathrm{C}$, carboxyl or amidogen -C, aliphatic $\mathrm{C}$ and aromatic - $\mathrm{C}$ all had significant and pervasive effects on the formation of soil macro-aggregates. Polysaccharide-C acts as a binding agent in soil and is elevated primarily in macro-aggregates (Sarker et al., 2018; Guo et al., 2020). In our study, rice husk application increased the percentage of polysaccharide-C (Table 2) that could favor formation of soil macro-aggregates and increase aggregate stability. This support the hypothesis of a rapid improvement in aggregate stability following addition of fresh organic residues that provide a source of labile polysaccharides (Sarker et al., 2018). In addition, preferential microbial consumption of carbohydrates or alkyl-rich compounds can alter soil structure (Chevallier et al., 2010). In particular, aliphatic-C fractions were positively associated to aggregate stability, indicating a promoting effect on soil structure. Accordingly, aliphatic-C is important in organo-mineral interactions and is found throughout the microstructure of aggregates (Kinyangi et al., 2006). In our experiments, we found significant positive correlations with aggregate stability (e.g., MWD) as well as Fe-ox. This supports the aggregate formation model of micro-aggregates through interactions between mineral surfaces and aliphatic-C with little protection in early stages of formation (Lehmann et al., 2001).

Generally, addition of organic material significantly improved SOM content and hence the stability of soil aggregate. However, these effects were highly variable depending on amendment types as shown by our soil aggregate stability and size distribution results (Fig. 1a). Rice husk addition significantlly increased the proportion of $>2 \mathrm{~mm}$ aggregates possibly due to higher HM and polysaccharide-C content. Chicken manure application increase Fe-ox due to soil acidification and increase aliphatic-C content that in turn, may have increased the proportion of small macro-aggregates. However, rice husks are more recalcitrant to decomposition and excessive accumulation can increase soil preferential flow resulting in loss of fertilizer and other soil components (Anikwe 2000; Pratiwi et al., 2016). Hence, rice husks and chicken manure combined application may be better increasing soil aggregate stability and size distribution. However, further studies are still necessary to examine the proportion between rice husks and chicken manure increasing soil productivity.

\section{Conclusions}

Proper and sustainable management of organic material additions to soils can increase the proportion of $>0.25 \mathrm{~mm}$ aggregates and promotes aggregate stability. Organic material application affects the aggregate stability, either directly by its organic matter contents and architectural features or indirectly by altering the composition of soil humus and $\mathrm{C}$ functional groups, iron oxides and other key factors that control particle aggregation. Rice husk addition significantly increased the proportion of $>2 \mathrm{~mm}$ aggregates, possibly due to higher HM and polysaccharide-C content. Chicken manure application increased soil Fe-ox content due to soil acidification and increased soil aliphatic-C content that in turn, increased the proportion of 1-2 $\mathrm{mm}$ aggregates. We suggest that the combinations of chicken manure and rice husks are a positive and effective agriculture measure to improve greenhouse vegetable soil structure.

\section{Acknowledgments}

This work was financially supported by the National Key Projects (2017YFD0200208-3), the Soil and Cultivation Position of Modern Agricultural Technology System Innovation Team in Shandong Province (SDAIT17-05), the Natural Science Fund in Shandong Province (ZR2017MC015), the Key Research and Development Plan of Shandong (2015GNC111014), and the Key Research and Development Plan of Shandong (2019GNC106015).

\section{References}


Adhikari, D., \& Yang, Y. (2015). Selective stabilization of aliphatic organic carbon by iron-oxide. Scientific Reports , 5, 11214. DOI: 10.1038/srep11214

Anikwe, M.A.N. (2000). Amelioration of a heavy clay loam soil with rice husk dust and its effect on soil physical properties and maize yield. Bioresource Technology , 74(2), 169-173. DOI: 10.1016/S09608524(00)00007-9

Baes, A.U., \& Bloom, P.R. (1989). Diffuse reflectance and transmission Fourier transform infrared (DRIFT) spectroscopy of humic and fulvic acids. Soil Science Society of America Journal , 53, 695-700. DOI: $10.2136 /$ sssaj1989.03615995005300030008x

Chevallier, T., Woignier, T., Toucet, J., \& Blanchart, E. (2010). Organic carbon stabilization in the fractal pore structure of Andosols. Geoderma , 159, 182-188 DOI: 10.1016/j.geoderma.2010.07.010

Chien, C.C., Huang, Y.P., Sah, J.G., Cheng, W.J., Chang, R.Y., \& Lu, Y.S. (2011). Application of rice husk charcoal on remediation of acid soil. Materials Science Forum , 685, 169-180. DOI: 10.4028/www.scientific.net/MSF.685.169

Dou, S., 2010. Soil organic matter. Science Press, Beijing

Guo, L., Shen, J., Li, B., Li, Q., Wang, C., Guan, Y., \& Li, H. (2020). Impacts of agricultural land use change on soil aggregate stability and physical protection of organic C. Science of the Total Environment , 707, 136049. DOI: $10.1016 /$ j.scitotenv.2019.136049

Janik, L.J., J. Skjemstad, K. Shepherd, L. \& Spouncer. (2007). The prediction of soil carbon fractions using mid-infrared-partial least square analysis. Australian Journal of Soil Research , 45:73-81. DOI: 10.1071/SR06083

Kinyangi, J., Solomon, D., Liang, B., Lerotic, M., Wirick, S., \& Lehmann, J. (2006). Nanoscale biogeo complexity of the organomineral assemblage in soil: application of STXMmicroscopy and C 1 s-NEXAFS Spectroscopy. Soil Science Society of America Journal , 70, 1708-1718. DOI: 10.2136/sssaj2005.0351

Klotzbucher, T., Kaiser, K., Filley, T.R., \& Kalbitz, K. (2013). Processes controlling the prodution of aromatic water-soluble organic matter during litter decomposition.Soil Biology and Biochemistry , 67, 133139. DOI: $10.1016 /$ j.soilbio.2013.08.003

Kuwatsuka, S., Watanabe, A., Itoh, K., \& Arai, S. (1992). Comparison of two methods of preparation of humic and fulvic acids, IHSS method and NAGOYA method. Soil Science and Plant Nutrition, 38:23-30. DOI: $10.1080 / 00380768.1992 .10416948$

Kuzyakov, Y., 2010. Priming effects: Interactions between living and dead organic matter. Soil Biology and Biochemistry , 42, 1363-1371. DOI:10.1016/j.soilbio.2010.04.003

Lehmann, J., da Silva Cravo, M., \& Zech, W. (2001). Organic matter stabilization in a Xanthic Ferralsol of the central Amazon as affected by single trees: chemical characterization of density, aggregate, and particle size fractions.Geoderma , 99(1-2), 147-168. DOI: 10.1016/S0016-7061(00)00070-7

Li, X.Y. (1997). Soil Chemistry and Experimental Guidelines. China Agriculture Press, Beijing.

Mamedov, A.I., Bar-Yosef, B., Levkovich, I., Rosenberg, R., Silber, A., Fine, P., \& Levy, G. J. (2014). Amending soil with sludge, manure, humic acid, orthophosphate and phytic acid: effects on aggregate stability. Soil Research . 52(4), 317-326. DOI: 10.1071/SR13334

Movasaghi, Z., S. Rehman, \& I. ur Rehman. (2008). Fourier transform infrared (FTIR) spectroscopy of biological tissues. Applied Spectroscopy Reviews , 43:134-179. DOI: 10.1080/05704920701829043

Parikh, S.J., K.W. Goyne, A.J. Margenot, F.N.D., Mukome, \& F.J. Calderon. (2014). Soil chemical insights provided through vibrational spectroscopy. In: D.L. Sparks, editor, Advances in Agronomy . Academic Press, Waltham, MA. p. 1-148. DOI: 10.1016/B978-0-12-800132-5.00001-8 
Parwada, C., Van, Tol, J. (2019). Effects of litter quality on macroaggregates reformation and soil stability in different soil horizons[J]. Environment, Development and Sustainability, 21(3),1321-1339. DOI: 10.1007/s10668-018-0089-z

Peltre, C., Bruun, S., Du, C., Thomsen, I.K., \& Jensen, L.S. (2014). Assessing soil constituents and labile soil organic carbon by mid-infrared photoacoustic spectroscopy. Soil Biology and Biochemistry , 77, 41-50. DOI: $10.1016 /$ j.soilbio.2014.06.022

Pratiwi, E.P.A., Hillary, A.K., Fukuda, T., \& Shinogi, Y. (2016). The effects of rice husk char on ammonium, nitrate and phosphate retention and leaching in loamy soil.Geoderma , 277, 61-68. DOI: 10.1016/j.geoderma.2016.05.006

Qiao, J., Li, X., Li, F., Liu, T., Young, L. Y., \& Huang, W. (2019). Humic substances facilitate arsenic reduction and release in flooded paddy soil. Environmental Science $\mathscr{E}$ Technology, 53(9), 5034-5042. DOI: 10.1021/acs.est.8b06333

Sander, S., Mosley, L.M., \& Hunter, K.A. (2004). Investigation of interparticle forces in natural waters: Effects of adsorbed humic acids on iron oxide. Environmental Science $\& 3$ Technology, 38, 4791-4796. DOI: $10.1021 / \mathrm{es} 049602 \mathrm{z}$

Sarker, T. C., Incerti, G., Spaccini, R., Piccolo, A., Mazzoleni, S., \& Bonanomi, G. (2018). Linking organic matter chemistry with soil aggregate stability: Insight from ${ }^{13} \mathrm{C}$ NMR spectroscopy. Soil Biology and Biochemistry , 117, 175-184. DOI: 10.1016/j.soilbio.2017.11.011

Six, J., Elliott, E.T., \& Paustian, K. (2000). Soil structure and soil organic matter II. Anormalized stability index and the effect of mineralogy. Soil Science Society of America Journal , 64(3):1042-1049. DOI: $10.2136 /$ sssaj2000.6431042x

Song, X., Liu, J., Jin, S., He, X., Liu, S., Kong, X., \& Dong, F. (2018). Differences of C sequestration in functional groups of soil humic acid under long term application of manure and chemical fertilizers in North China. Soil \&3 Tillage Research, 176, 51-56. DOI: 10.1016/j.still.2017.11.004

Stevenson, F.J. (1994). Humus Chemistry: Genesis, Composition, Reactions; John Wiley and Sons: New York.

Tadashi, T., \& Randy, A.D. (2016). Nature, properties and function of aluminum-humus complexes in volcanic soils. Geoderma . 263, 110-121. DOI: 10.1016/ j. geoderma. 2015.08.032

Wang, X.J., Jia, Z.K., Liang, L.Y., Yang, B.P., Ding, R.X., Nie, J.F., \& Wang, J.P. (2015). Maize straw effects on soil aggregation and other properties in arid land. Soil \& Tillage Research, 153, 131-16. DOI: 10.1016/j.still.2015.05.001

Wang, Y., Gao, S., Li, C., Zhang, J., \& Wang, L. (2016). Effects of temperature on soil organic carbon fractions contents, aggregate stability and structural characteristics of humic substances in a Mollisol. Journal of Soils and Sediments , 16(7), 1849-1857. DOI: 10.1007/s11368-016-1379-4

Wen, Y., Liu, W., Deng, W., He, X., \& Yu, G. (2019). Impact of agricultural fertilization practices on organo-mineral associations in four long-term field experiments: implications for soil c sequestration.Science of the Total Environment , 651, 591-600. DOI: 10.1016/j.scitotenv.2018.09.233

Xu, L., Wang, C.Y., Zhu, J.X., Gao, Y., Li, M.L., Lv, Y.L., Yu, G.R., \& He, N.P. (2018). Latitudinal patterns and influencing factors of soil humic carbon fractions from tropical to temperate forests. Journal of Geographical Sciences , 28, 15-30. DOI: 10.1007/s11442-018-1456-2

Zhang, J.J., Hu, F., Li, H.X., Gao, Q., Song, X.Y., Ke, X.K., \& Wang, L.C. (2011). Effects of earth worm activity on humus composition and humic acid characteristics of soil in a maize residue amended rice-wheat rotation agroecosystem. Applied Soil Ecology , 51:1-8. DOI: 10.1016/j.apsoil.2011.08.004 
Zhang, J.J., Wei, Y.X., Liu, J.Z., Yuan, J.C., Liang, Y., Ren, J., \& Cai, H.G. (2019). Effects of maize straw and its biochar application on organic and humic carbon in water-stable aggregates of a Mollisol in Northeast China: a five-year field experiment. Soil \& Tillage Research , 190, 1-9. DOI: 10.1016/j.still.2019.02.014

Zhao, H., Shar, A. G., Li, S., Chen, Y., Shi, J., Zhang, X., \& Tian, X. (2018). Effect of straw return mode on soil aggregation and aggregate carbon content in an annual maize-wheat double cropping system. Soil \& Tillage Research , 175, 178-186. DOI: 10.1016/j.still.2017.09.012

Zhao, J., Chen, S., Hu, R., \& Li, Y. (2017). Aggregate stability and size distribution of red soils under different land uses integrally regulated by soil organic matter, and iron and aluminum oxides.Soil $\&$ Tillage Research , 167, 73-79. DOI: 10.1016 /j. still. 2016.11.007

Zhao, X.M., Zhu, M.L., Guo, X.X., Wang, H.B., Sui, B., \& Zhao, L.P. (2019). Organic carbon content and humus composition after application aluminum sulfate and rice straw to soda saline-alkaline soil.Environmental Science and Pollution Research , 26, 13746-13754. DOI: 10.1007/s11356-018-2270-1

Zhu, F., Li, Y., Xue, S., Hartley, W., \& Wu, H. (2016). Effects of iron-aluminium oxides and organic carbon on aggregate stability of bauxite residues. Environmental Science and Pollution Research, 23(9), 9073-9081. DOI: $10.1007 / \mathrm{s} 11356-016-6172-9$

\section{Hosted file}

Fig.docx available at https://authorea.com/users/331612/articles/458228-soil-aggregatestability-and-carbon-fractions-in-soils-containing-organic-matter-additions-inintensive-greenhouse-vegetable-fields

\section{Hosted file}

Table.docx available at https://authorea.com/users/331612/articles/458228-soil-aggregatestability-and-carbon-fractions-in-soils-containing-organic-matter-additions-inintensive-greenhouse-vegetable-fields 